\title{
Homologated amino acids with three vicinal fluorines positioned along the backbone: development of a stereoselective synthesis
}

\author{
Raju Cheerlavancha ${ }^{1}$, Ahmed Ahmed ${ }^{1}$, Yun Cheuk Leung ${ }^{1}$, Aggie Lawer $^{1}$, \\ Qing-Quan Liu ${ }^{2}$, Marina Cagnes ${ }^{3}$, Hee-Chan Jang ${ }^{3}$, Xiang-Guo Hu ${ }^{2}$ and Luke Hunter ${ }^{* 1}$
}

Open Access

\author{
Full Research Paper \\ Address: \\ ${ }^{1}$ School of Chemistry, The University of New South Wales, Sydney \\ NSW 2052, Australia, ${ }^{2}$ National Engineering Research Center for \\ Carbohydrate Synthesis, Jiangxi Normal University, Nanchang, China \\ and ${ }^{3}$ School of Chemistry, The University of Sydney, Sydney NSW \\ 2006, Australia \\ Email: \\ Luke Hunter* - I.hunter@unsw.edu.au \\ ${ }^{*}$ Corresponding author \\ Keywords: \\ amino acids; conformation; deoxyfluorination; fluorine; \\ stereochemistry
}

Beilstein J. Org. Chem. 2017, 13, 2316-2325.

doi:10.3762/bjoc. 13.228

Received: 26 June 2017

Accepted: 09 October 2017

Published: 01 November 2017

This article is part of the Thematic Series "Organo-fluorine chemistry IV".

Associate Editor: K. N. Allen

(c) 2017 Cheerlavancha et al.; licensee Beilstein-Institut.

License and terms: see end of document.

\begin{abstract}
Backbone-extended amino acids have a variety of potential applications in peptide and protein science, particularly if the geometry of the amino acid is controllable. Here we describe the synthesis of $\delta$-amino acids that contain three vicinal $\mathrm{C}-\mathrm{F}$ bonds positioned along the backbone. The ultimately successful synthetic approach emerged through the investigation of several methods based on both electrophilic and nucleophilic fluorination chemistry. We show that different diastereoisomers of this fluorinated $\delta$-amino acid adopt distinct conformations in solution, suggesting that these molecules might have value as shape-controlled building blocks for future applications in peptide science.
\end{abstract}

\section{Introduction}

The incorporation of unnatural amino acids into a peptide structure can potentially reduce conformational disorder and hence improve the binding affinity of the peptide for its biological target. For example, conformationally rigid amino acids such as 1 (Figure 1) have been shown to dramatically affect the secondary structure of peptides within which they are contained, with consequent implications for the peptides' biological potency and selectivity [1]. A more subtle example of this concept is provided by the amino acid $\beta$-methylphenylalanine (2), which exerts conformational bias through acyclic means; steric interactions associated with the $\beta$-methyl group can affect the topography of peptides which once again affects the biological affinity and selectivity [2].

Extending the idea of acyclic shape control, amino acids with homologated backbones (e.g., 3-5, Figure 1) [3-10] provide op- 


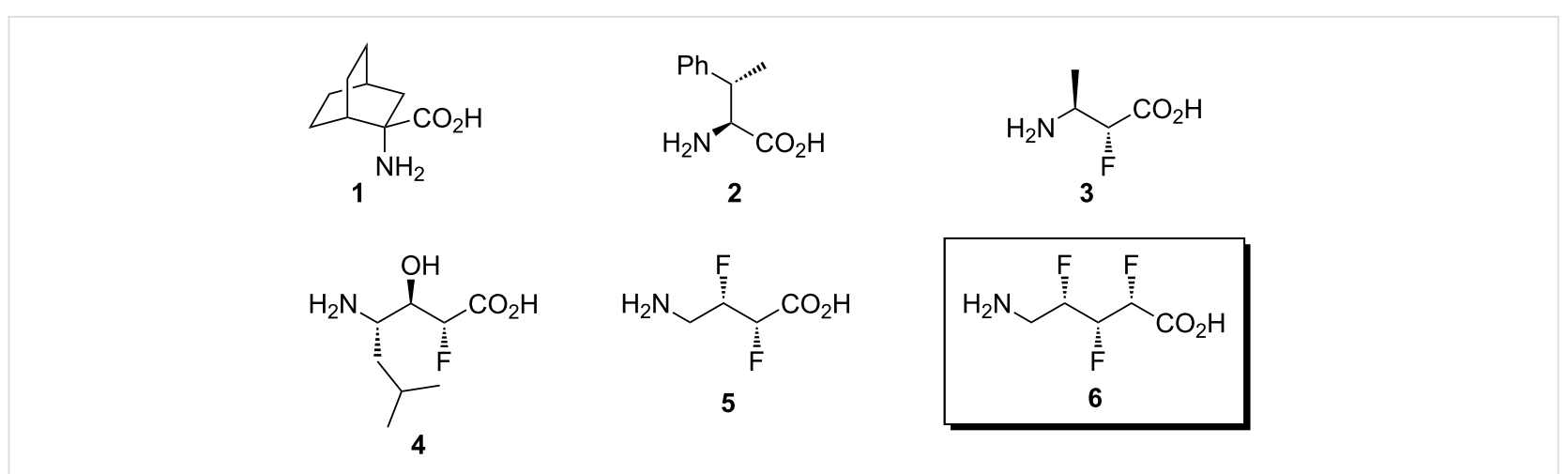

Figure 1: Examples of conformationally biased amino acids [1-10]. Compound 6 is a target of this work.

portunities for functionalisation in ways not possible in natural $\alpha$-amino acids. There is the ability to place heteroatoms along the amino acid backbone, or to incorporate two or more functionalised side chains per amino acid residue, and this results in a variety of stereochemical configurations that can affect the conformation. Organofluorine chemistry offers a particular attraction here, since fluorinated molecules (e.g., 3-5) tend to adopt predictable conformations due to hyperconjugative and/or dipole-dipole interactions associated with the $\mathrm{C}-\mathrm{F}$ bond [11$15]$.

Such a progression in the study of fluorinated amino acids develops into the concept of $\alpha, \beta, \gamma$-trifluoro- $\delta$-amino acids (e.g., 6, Figure 1). $\delta$-Amino acids such as $\mathbf{6}$ are of special interest because they have the same backbone length as a dipeptide of $\alpha$-amino acids, and thus may potentially be substituted for a two amino acid unit in a natural peptide without changing the overall length of the peptide [16]. The presence of three vicinal fluorine atoms on the amino acid backbone of $\mathbf{6}$ gives rise to eight possible stereoisomeric forms, which presents a synthetic challenge of stereocontrol. As an initial contribution towards the study of such compounds, we recently published a synthesis of two diastereoisomers of 6 (in protected form) [17]. We now disclose full details of the various synthetic approaches that were investigated towards the target $\mathbf{6}$, and the extensive troubleshooting that was required even within the approach that was ultimately successful. We also present here, for the first time, a qualitative NMR $J$-based conformational analysis of the free amino acids including $\mathbf{6}$.

\section{Results and Discussion}

Early in our efforts to develop a successful synthesis of $\mathbf{6}$, we realized that it might be possible to construct the repeating $(\mathrm{CHF})_{n}$ motif within the target molecule via an iterative synthetic approach (Scheme 1, boxed). We reasoned that an aldehyde such as 7 could undergo electrophilic fluorination, mediated by a chiral organocatalyst [18-20], to generate the fluorinated alde- hyde $\mathbf{8}$ as a single stereoisomer. Then, if the carbon chain of $\mathbf{8}$ could be extended by one atom to give the homologated aldehyde 9, fluorination could be repeated and the cycle could continue until the desired number of fluorine atoms was installed. This hypothetical approach had several attractions, including (i) the flexibility of being able to generate amino acids of different backbone lengths (e.g., 5, 6, Figure 1) via a unified strategy; (ii) an ability to access any stereoisomer of the target molecules (provided that the stereoselectivity in each fluorination step was catalyst-controlled); (iii) the lower toxicity of the electrophilic fluorination reagent NFSI (compared with nucleophilic fluorination reagents such as DeoxoFluor).

Accordingly, two aldehyde substrates (7a and $7 \mathbf{b})$ were prepared $[21,22]$, containing either a phthalimide or a Boc protecting group. Electrophilic fluorination was attempted according to the method developed by Jørgensen and co-workers (Scheme 1) [20]. Thus, the aldehyde 7a (or 7b) was treated with $\mathrm{N}$-fluorobenzenesulfonimide in the presence of the chiral organocatalyst $\mathbf{1 0}$, and after a certain period the fluorinated aldehyde product $\mathbf{8}$ was reduced in situ. Initial studies with substrate 7a (containing the phthalimide protecting group) suggested that the undesired difluorinated compound $\mathbf{1 2}$ was formed as the major product. An additional complication was that the phthalimide protecting group of $\mathbf{1 2}$ seemed to be at least partially sensitive to sodium borohydride [23]. In contrast, the substrate $\mathbf{7 b}$ (containing the Boc protecting group) was successfully converted into the desired fluorohydrin 11, albeit in poor yield. The optical purity of $\mathbf{1 1}$ was established through Mosher ester analysis (see Supporting Information File 1).

With the fluorohydrin 11 in hand (Scheme 1), the next task was to extend the carbon chain by one atom. The alcohol 11 was first converted into the corresponding tosylate (Scheme 1), but when this tosylate was subsequently treated with cyanide the undesired disubstituted product $\mathbf{1 4}$ was formed in $40 \%$ yield. Unfortunately, despite varying the reaction stoichiometry it was 


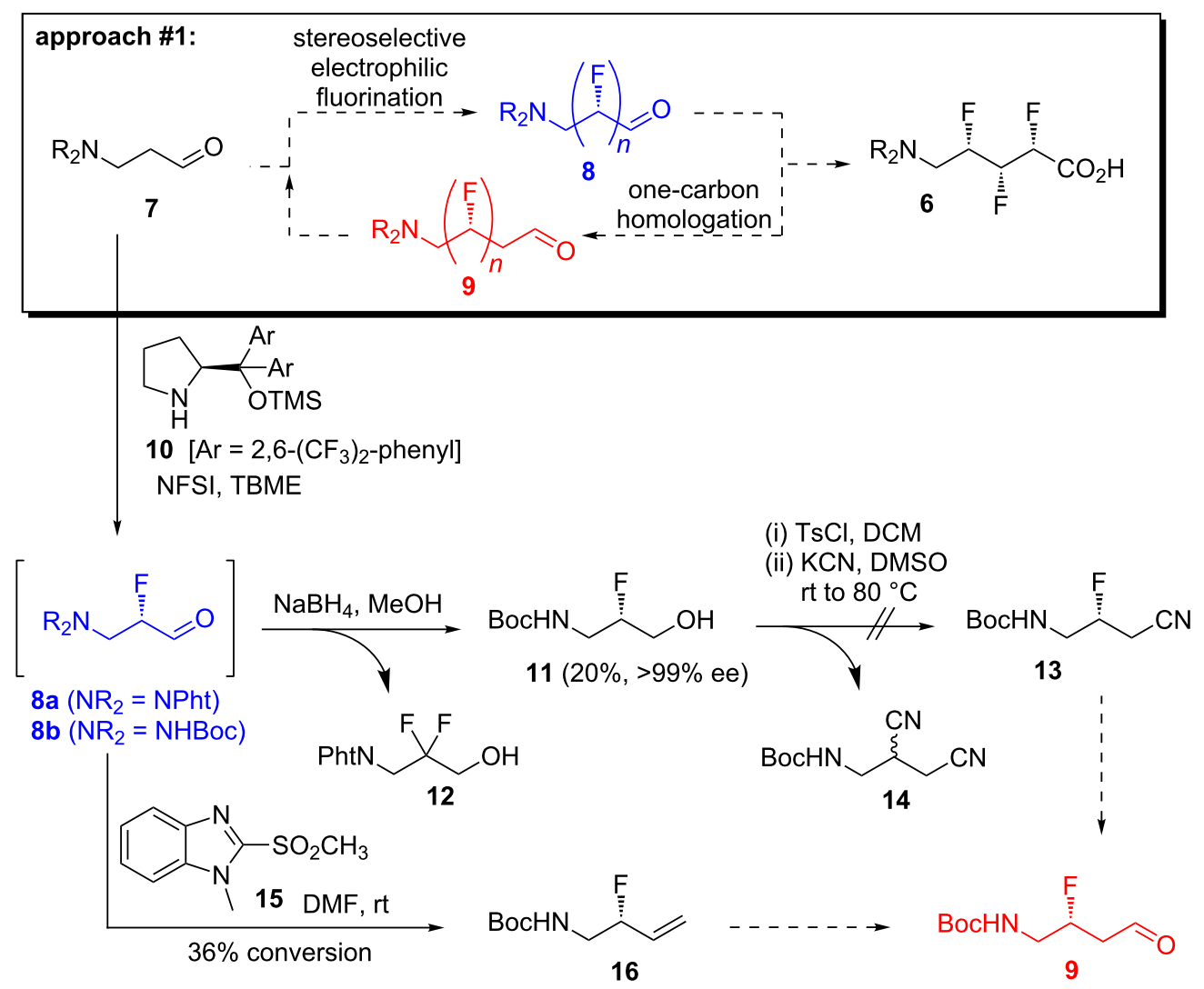

Scheme 1: The first synthetic approach.

not possible to isolate any of the desired product 13 . It is possible that varying the reaction solvent might alter the reactivity profile, but this was not investigated in this study. We did explore a triflate leaving group in this reaction (not shown), but this gave a complex mixture of products upon treatment with cyanide. As a further disappointment, the disubstituted product 14 appeared to be racemic, which implied that an elimination-addition sequence had taken place, which in turn suggested that intermediates such as $\mathbf{9}$ might be rather unstable.

An alternative strategy for extending the carbon backbone was needed. Grubbs and co-workers recently showed that $\beta$-fluoroaldehydes (e.g., 9, Scheme 1) can be synthesized in one step from allylic fluorides (e.g., 16) via Wacker-type oxidation [24]. Other methods for converting allylic fluorides into $\beta$-fluoroaldehydes are also known $[25,26]$. Therefore we turned our attention to converting the fluorinated aldehyde $\mathbf{8 b}$ (Scheme 1) into the allylic fluoride 16. The crude fluorinated aldehyde $\mathbf{8 b}$ was treated with a variety of olefination reagents (e.g., Tebbe; Wittig; reagent 15 [27]). Unfortunately, however, the desired allylic fluoride $\mathbf{1 6}$ was either not formed or was very unstable, which meant that the subsequent Wacker-type oxidation [24] to 9 could not be attempted.
Concurrent with the homologation attempts described above (Scheme 1), some model studies were performed (Table 1) to ascertain the feasibility of performing $\alpha$-fluorinations on other $\beta$-fluorinated carbonyl compounds besides 9. Thus, $\beta$-fluoroaldehyde 17 which was synthesized by an independent method (see Supporting Information File 1) was treated with NFSI and catalyst $\mathbf{1 0}$ according to Jørgensen's fluorination protocol [20] (Table 1, entry 1). However, this resulted in a complex mixture of products within which the desired $\alpha, \beta$-difluorinated product could not be identified. The alternative model substrate 18 (see Supporting Information File 1) was next investigated (Table 1, entry 2). Unfortunately, however, compound 18 proved unstable to silica and so it was not possible to obtain sufficiently pure material for a meaningful $\alpha$-fluorination test reaction to be performed. The low stability of $\beta$-fluoroaldehydes appeared to be a general phenomenon, and so an attempt was next made to generate such a substrate in situ via the oxidation of $\beta$-fluoroalcohol 19 (Table 1, entry 3), followed immediately by a fluorination reaction. However, this did not yield any of the desired vicinal difluorinated material. It is possible that alternative electrophilic fluorinating reagents such as Selectfluor [28] could give different results, but this was not investigated in this work. 


\begin{tabular}{|c|c|c|c|}
\hline Entry & Substrate & Conditions & Outcome \\
\hline 1 & 17 & (i) $10, \mathrm{NFSI}, \mathrm{TBME}, \mathrm{rt}$; (ii) $\mathrm{NaBH}_{4}, \mathrm{MeOH}$ & complex mixture \\
\hline 2 & 18 & $\begin{array}{l}\text { substrate } 18 \text { decomposed on silica, so no } \\
\text { a-fluorination reactions could be attempted }\end{array}$ & $\mathrm{N} / \mathrm{A}$ \\
\hline 3 & 20 & $\mathrm{KOt}$-Bu, NFSI, THF, rt & $\begin{array}{l}\text { starting material } 20 \\
\text { recovered }\end{array}$ \\
\hline 4 & & KHMDS, NFSI, THF, $-78^{\circ} \mathrm{C}$ & complex mixture \\
\hline
\end{tabular}

In a final attempt to develop an iterative fluorination/homologation strategy (Scheme 1, boxed), we considered whether an ester could be employed as the repeating unit, instead of an aldehyde. Accordingly, the model ester 20 (see Supporting Information File 1) was treated with an electrophilic fluorine source under basic conditions (Table 1, entries 3 and 4). Unfortunately, however, these attempts either returned unreacted starting material, or gave rise to a complex mixture of products, rather than the desired $\alpha, \beta$-difluorinated ester.

Since major difficulties were encountered in both of the key steps of the proposed iterative fluorination/homologation approach (Scheme 1, boxed), we were forced to conclude that this was not a viable route to $\alpha, \beta, \gamma$-trifluoro- $\delta$-amino acids 6 .

The next approach that was investigated is shown in Scheme 2. Having learned that homologation reactions involving fluorinated substrates were not facile, we decided to start the new approach with a full-length carbon chain in the form of piperidinedione 21. We envisaged that a sequence of reactions - two electrophilic fluorinations [29-31] followed by reduction and deoxyfluorination - would deliver the target molecule 6 .

Accordingly, two piperidinedione substrates (21a and 21b) were prepared [32,33], containing a Boc or a benzyl protecting group, respectively (Scheme 2). Substrate 21a was first treated with Selectfluor in acetonitrile according to a mild protocol developed by Smith and co-workers for the $\alpha$-fluorination of ke- tones [31]. However, ${ }^{1} \mathrm{H}$ NMR and ${ }^{19}$ F NMR analysis of the crude reaction mixture revealed that the only identifiable product was the undesired gem-difluorinated compound $\mathbf{2 5}$ (Scheme 2), which was obtained along with a significant amount of unreacted starting material 21a (see Supporting Information File 1). When the alternative substrate 21b was exposed to a variety of different electrophilic fluorinating conditions (Scheme 2), a new reaction outcome was observed: in this case, the only identifiable product was the undesired dimeric species 26, which was consistently obtained in reasonably high yields (see Supporting Information File 1). This product presumably arose through aldol condensation of the readily enolisable ketone 22 with another molecule of 21. Overall then, it was concluded that approach \#2 was not a viable strategy for synthesising target $\mathbf{6}$. Alternative substrates based on the piperidine-2,5-dione scaffold might prove more tractable in the future, but this has not yet been investigated in our laboratories.

Since the first two approaches to target 6 (Scheme 1 and Scheme 2) were unsuccessful, we reasoned that a better-precedented synthetic method was needed. O'Hagan and co-workers have previously reported a concise method for synthesising compounds that contain three vicinal $\mathrm{C}-\mathrm{F}$ bonds [34]; their method commences with an epoxy alcohol, which undergoes three successive nucleophilic substitutions with fluoride (i.e., deoxyfluorination of the alcohol, epoxide ring opening with fluoride, then deoxyfluorination). We therefore sought to apply O'Hagan's method to the target $\mathbf{6 b}$ (Scheme 3, boxed). 
approach \#2:

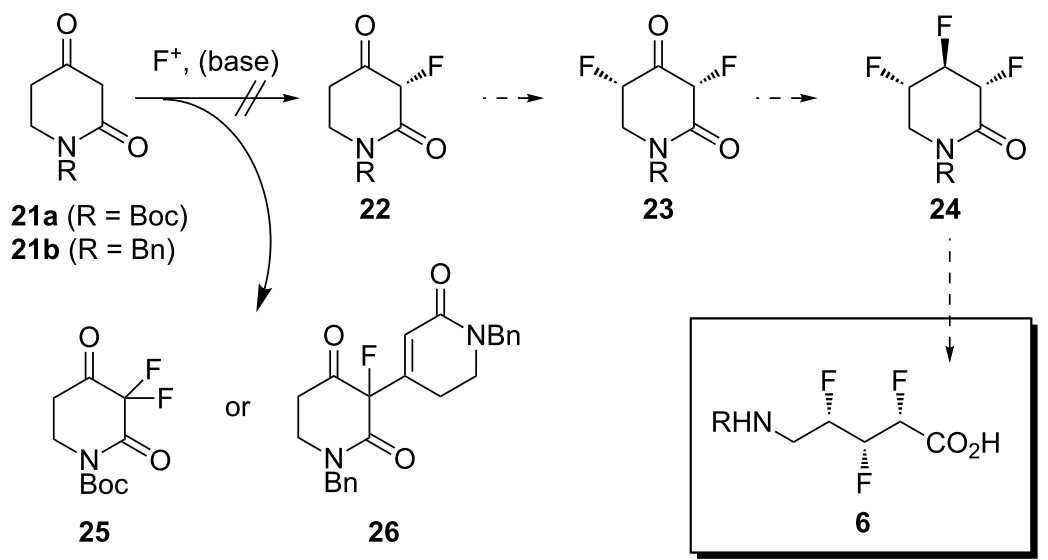

Scheme 2: The second synthetic approach.

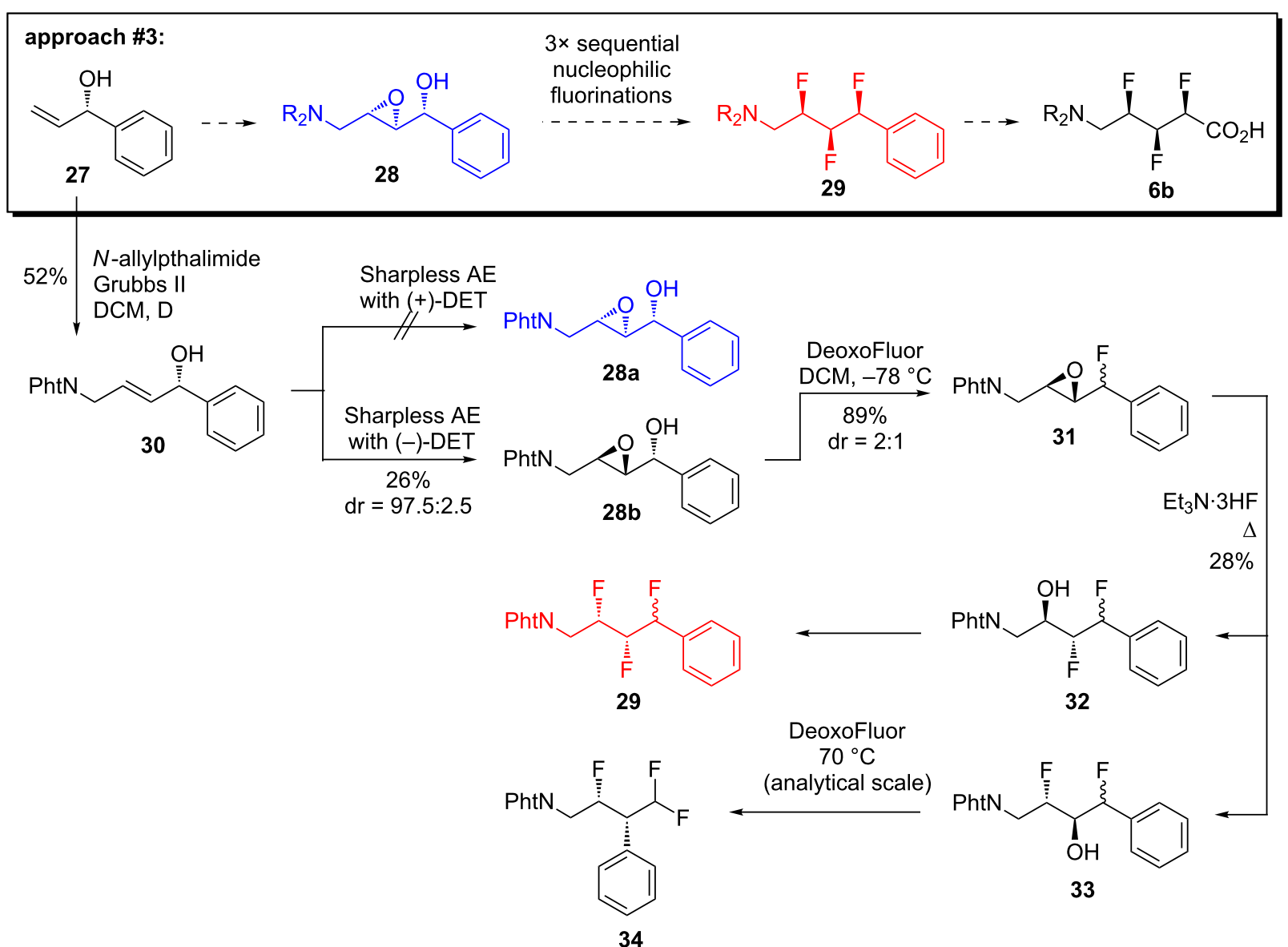

Scheme 3: The third synthetic approach.

Accordingly, the enantiopure allylic alcohol 27 [35] was extended through a cross-metathesis reaction to deliver the disubstituted alkene 30 (Scheme 3). Compound $\mathbf{3 0}$ became the sub- strate for an attempted Sharpless asymmetric epoxidation reaction using (+)-DET (Scheme 3); however, none of the desired product 28a was observed in this case, presumably due to a sub- 
strate/catalyst mismatch effect. Therefore, the epoxidation reaction was re-attempted using (-)-DET (Scheme 3); this successfully afforded the syn,anti-epoxy alcohol $\mathbf{2 8 b}$ with good stereoselectivity, albeit in poor yield. One reason for the low yield of $\mathbf{2 8 b}$ was the difficulty in its chromatographic separation from the byproducts of the epoxidation reaction. Nevertheless, a sufficient quantity of $\mathbf{2 8 \mathbf { b }}$ was obtained to proceed some way with the synthesis. Compound $\mathbf{2 8 b}$ was treated with DeoxoFluor at low temperature, in order to affect a deoxyfluorination of the benzylic alcohol. This reaction gave the product $\mathbf{3 1}$ in high yield, but unfortunately with poor stereoselectivity, presumably due to a competing $\mathrm{S}_{\mathrm{N}} 1$-type reaction mechanism $[36,37]$. This reaction was not fully optimised; instead, the available quantity of the fluoroepoxide $\mathbf{3 1}$ was carried forward so that some idea could be obtained about the feasibility of the subsequent steps in the synthesis. Thus, the fluoroepoxide $\mathbf{3 1}$ (as a mixture of diastereoisomers) was treated with $\mathrm{Et}_{3} \mathrm{~N} \cdot 3 \mathrm{HF}$ according to O'Hagan's method [34] (Scheme 3). This did effect epoxide-opening to some extent, but the reaction was rather unsatisfactory because it was low-yielding and non-regioselective, which made full characterisation of the product mixture (32/33) impossible. Nevertheless, an analytical-scale final fluorination reaction was attempted (Scheme 3 ) because this was anticipated to converge some of the compounds into a simpler product mixture. Analysis of the crude reaction mixture by ${ }^{19} \mathrm{~F}$ NMR revealed that the desired product 29 may have been formed in small quantity. However, there was clear evidence that a gem-difluorinated compound had also formed: presumably this was compound $\mathbf{3 4}$ arising through neighbouring group participation and migration of the phenyl group [38]. A similar problem was encountered in the synthesis of $\alpha, \beta$-difluorinated- $\gamma$-amino acids (e.g., 5, Figure 1), which was being investigated in parallel $[5,6]$.

At this stage, it was clear that O'Hagan's method [34] (Scheme 3) was the most promising strategy that had been examined so far. But four major obstacles remained: first, the starting material 27 was volatile and difficult to stockpile; second, the purification of epoxy alcohol $\mathbf{2 8 b}$ was troublesome; third, the fluorination of $\mathbf{2 8} \mathbf{b}$ proceeded with poor stereoselectivity; and fourth, the final fluorination reaction suffered from an undesired rearrangement side-reaction. We subsequently found that all four of these problems could be solved by making a single change to the synthesis: namely, by introducing a $p$-nitro group onto the aryl ring of the starting material, 35 (Scheme 4) [17].

A benefit of the $p$-nitro group immediately became apparent: the starting material 35 [35] (Scheme 4) was less volatile and hence easier to stockpile than its unsubstituted counterpart 27 (Scheme 3). Compound 35 was carried through the same set of reactions that were described previously for substrate 27 (Scheme 3). Thus, 35 underwent a cross metathesis reaction to furnish 36 in good yield (Scheme 4). Compound 36 then became the substrate for a Sharpless asymmetric epoxidation reaction, which delivered 37 with very high stereoselectivity (Scheme 4). The $p$-nitro group of $\mathbf{3 7}$ played another useful role here: compound $\mathbf{3 7}$ was rather insoluble, so it could be efficiently purified simply by triturating the crude product mixture with toluene, a procedure which afforded 37 in much higher yield than was obtained for the epoxy alcohol $\mathbf{2 8 b}$ lacking the p-nitro group (Scheme 3). Compound 37 then underwent the first deoxyfluorination reaction to give compound 38a in excellent yield (Scheme 4). The presence of the $p$-nitro group did improve the stereoselectivity of this reaction somewhat, but it was found that the inclusion of the additive TMS-morpholine [36,37] was also required to ensure a high diastereoisomeric excess of 38a. The epoxide 38a was then ring-opened using $\mathrm{Et}_{3} \mathrm{~N} \cdot 3 \mathrm{HF}$ to deliver the difluorodiol 39a as a mixture of regioisomers. This mixture subsequently converged during the next deoxyfluorination reaction (Scheme 4). Gratifyingly, the $p$-nitro group of 39a was found to completely shut down the neighbouring group participation pathway; the desired trifluoroalkane 40a was obtained in good yield with no evidence of rearrangement or epimerization.

It was also possible to modify the synthesis shown in Scheme 4 to produce the all-syn trifluoroalkane 40b. Thus, the alcohol 37 underwent a Mitsunobu-type inversion of configuration, and O'Hagan's series of three consecutive fluorination reactions [34] were subsequently applied to successfully deliver the allsyn trifluoroalkane 40b (Scheme 4) [17].

Trifluoroalkanes 40a and 40b (Scheme 4) were advanced intermediates along the route towards the target trifluorinated amino acids (6). To complete the synthesis, the final requirements were to oxidise the aryl moiety into a carboxylic acid, and to deprotect the amino group. However, the $p$-nitro group of 40a,b now posed a complication, because aryl oxidation reactions are only facile for electron-rich systems $[39,40]$. Unsurprisingly, when the oxidation reaction was attempted under standard $\mathrm{NaIO}_{4} / \mathrm{RuCl}_{3}$ conditions $[39,40]$ with the nitroaryl substrate $\mathbf{4 0 a}$, no reaction was observed and the starting material was recovered intact.

Therefore, in order to identify a suitable method converting 40a,b into 6a,b (Scheme 4), model studies was undertaken using the simplified substrate $\mathbf{4 1}$ (Table 2). Initially, attempts were made to reduce $\mathbf{4 1}$ into the corresponding aniline $\mathbf{4 2}$, with a view to its subsequent elaboration, e.g., via diazotization. However, a variety of reduction conditions resulted either in no observable reaction (Table 2, entries 1 and 2), or else in defluo- 


\section{approach \#4:}

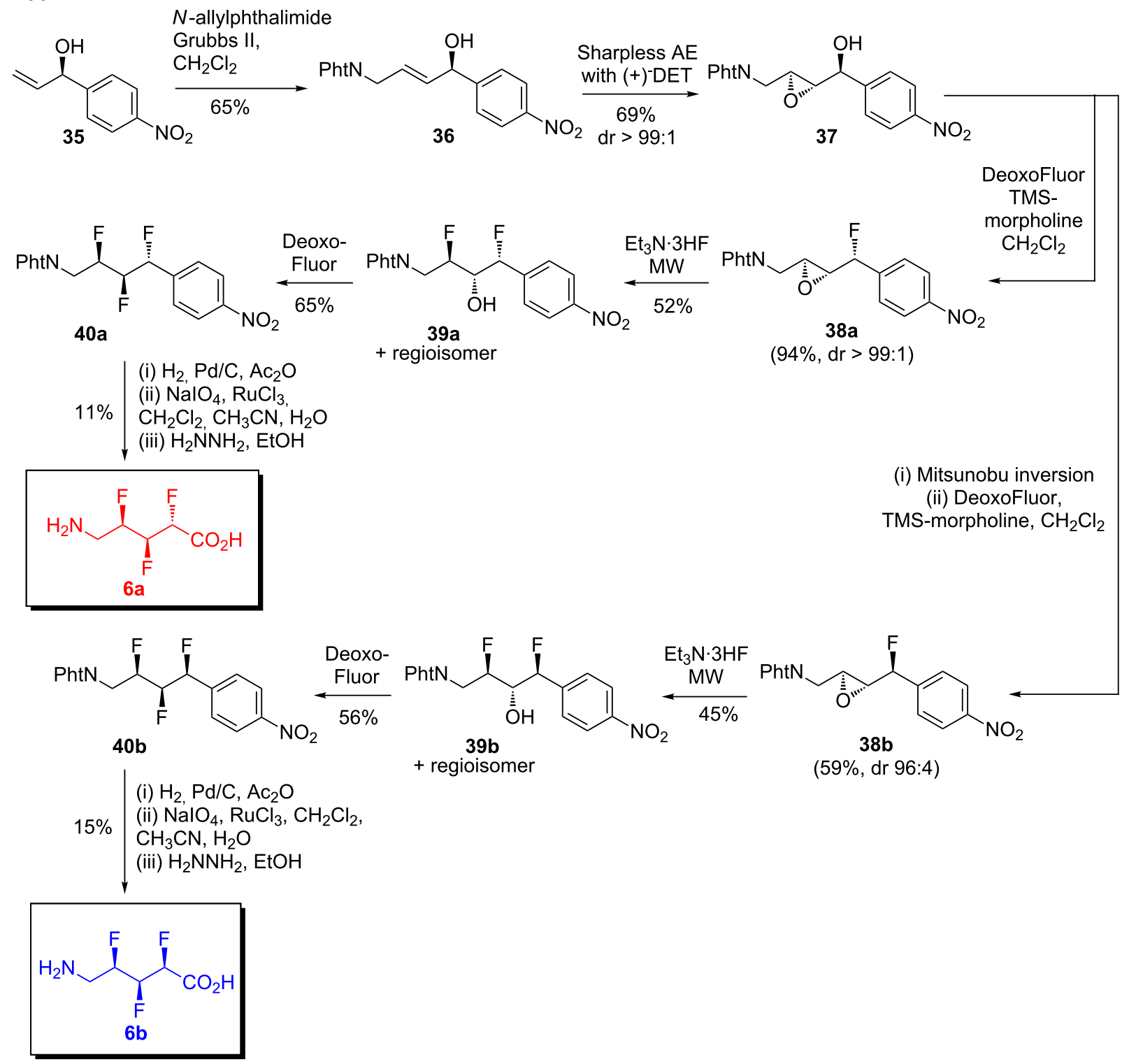

Scheme 4: The fourth synthetic approach (partially reproduced from ref. [17]).

rination at the benzyl position (Table 2, entry 3). The latter proceess is precedented [41]. Since none of the reductions to arylamines were successful, an alternative approach was investigated in which the nitroarene group would be converted into the corresponding acetanilide 43 . If this approach were successful, it was envisaged that the acetanilide $\mathbf{4 3}$ could be directly oxidised to carboxylic acid $\mathbf{4 4}$, thereby bypassing any diazotization process. Hydrogenation of $\mathbf{4 1}$ with $10 \% \mathrm{Pd} / \mathrm{C}$ in the presence of acetic anhydride allowed the isolation of acetanilide $\mathbf{4 3}$ in moderate yields (Table 2, entries 4-6). It was found that the acetic anhydride solvent needed to be freshly distilled in every case in order for the reaction to be successful. The reaction duration was another significant determinant of the yield of $\mathbf{4 3}$ (Table 2, entries 4-6), since the over-reduced (i.e., benzylic defluorination) product was still produced in varying amounts. The subsequent oxidation of $\mathbf{4 3}$ was successfully achieved using sodium metaperiodate and ruthenium chloride (Table 2) $[39,40]$, with the desired carboxylic acid $\mathbf{4 4}$ being obtained in $31 \%$ yield.

Having established the conditions necessary for the conversion of the nitroaryl group in model system 41 (Table 2), the procedure could now be applied to the trifluoroalkanes $40 \mathbf{a}, \mathbf{b}$ (Scheme 4). Thus, compound 40a was dissolved in freshly 
Table 2: Model studies that informed the final steps of the synthesis.

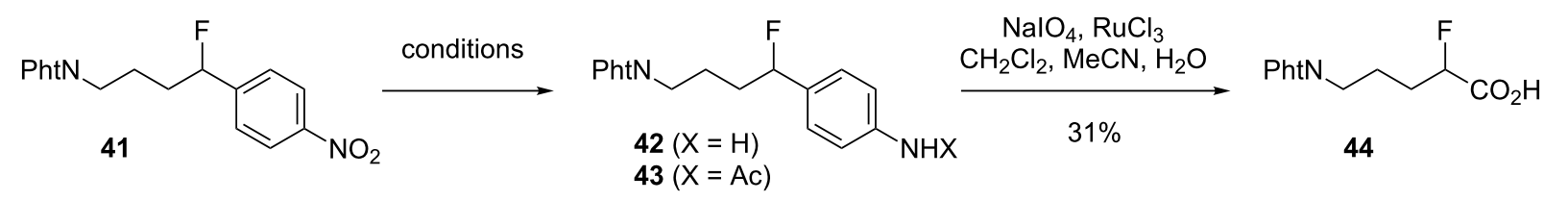

\begin{tabular}{|c|c|c|}
\hline Entry & Conditions & Outcome \\
\hline 1 & $\mathrm{Na}_{2} \mathrm{~S}_{2} \mathrm{O}_{4}$, aq HCl, rt, $20 \mathrm{~h}$ & no reaction \\
\hline 2 & $\mathrm{Na}_{2} \mathrm{~S}_{2} \mathrm{O}_{4}, \mathrm{HCl}$, ethanol, reflux, $4 \mathrm{~h}$ & no reaction \\
\hline 3 & $\mathrm{Pd} / \mathrm{C}$, ammonium formate, $\mathrm{THF}, 5 \mathrm{~h}$ & $\begin{array}{l}\text { defluorination of } 41 \text { observed by }{ }^{1} \mathrm{H} \text { and }{ }^{19} \mathrm{~F} \text { NMR } \\
\text { analysis of crude reaction mixture }\end{array}$ \\
\hline 4 & $\mathrm{H}_{2}, 10 \% \mathrm{Pd} / \mathrm{C}, \mathrm{Ac}_{2} \mathrm{O}, 3 \mathrm{~h}$ & $43(38 \%)$ \\
\hline 5 & $\mathrm{H}_{2}, 10 \% \mathrm{Pd} / \mathrm{C}, \mathrm{Ac}_{2} \mathrm{O}, 5 \mathrm{~h}$ & $43(58 \%)$ \\
\hline 6 & $\mathrm{H}_{2}, 10 \% \mathrm{Pd} / \mathrm{C}, \mathrm{Ac}_{2} \mathrm{O}, 18 \mathrm{~h}$ & $43(21 \%)$ \\
\hline
\end{tabular}

distilled acetic anhydride and subjected to hydrogenation over $\mathrm{Pd} / \mathrm{C}$ (Scheme 4). The reaction was monitored by TLC at short time intervals in order to avoid over-reduction. The starting material was consumed within $5 \mathrm{~h}$, but the expected acetanilide product (see Supporting Information File 1) was accompanied by varying quantities of a side-product that was tentatively identified either as an alternative rotamer of the acetanilide, or the corresponding imide (i.e., $\mathrm{ArNAc}_{2}$, see Supporting Information File 1). Although the formation of this imide would be unexpected, it was reasoned that it might still be a suitable substrate for the subsequent oxidation reaction. Accordingly, the product of the hydrogenation reaction was next treated with sodium metaperiodate and ruthenium trichloride (Scheme 4), and gratifyingly this delivered the desired trifluorinated carboxylic acid (see Supporting Information File 1) in moderate yield.
Finally, the pthalimide group was removed with hydrazine to give the target amino acid 6a (Scheme 4). The modest overall yield for this three-step sequence can be partially attributed to the challenge of purifying the penultimate and final compounds, which were of low molecular weight and very polar. Nevertheless, the first synthesis of a $\delta$-amino acid containing three vicinal fluorines on the backbone had been successfully completed. The all-syn target $\mathbf{6 b}$ was then obtained in a similar fashion from 40b (Scheme 4).

The ${ }^{1} \mathrm{H}$ and ${ }^{19} \mathrm{~F}$ NMR spectra of $\mathbf{6 a}$ and $\mathbf{6 b}$ were simulated (see Supporting Information File 1) in order to measure the spin-spin coupling constants and thereby gain information on the solution-state conformations (Figure 2). For 6a, the observed $J$ values about the $\mathrm{C} \alpha-\mathrm{C} \beta$ and $\mathrm{C} \beta-\mathrm{C} \gamma$ bonds are interme-

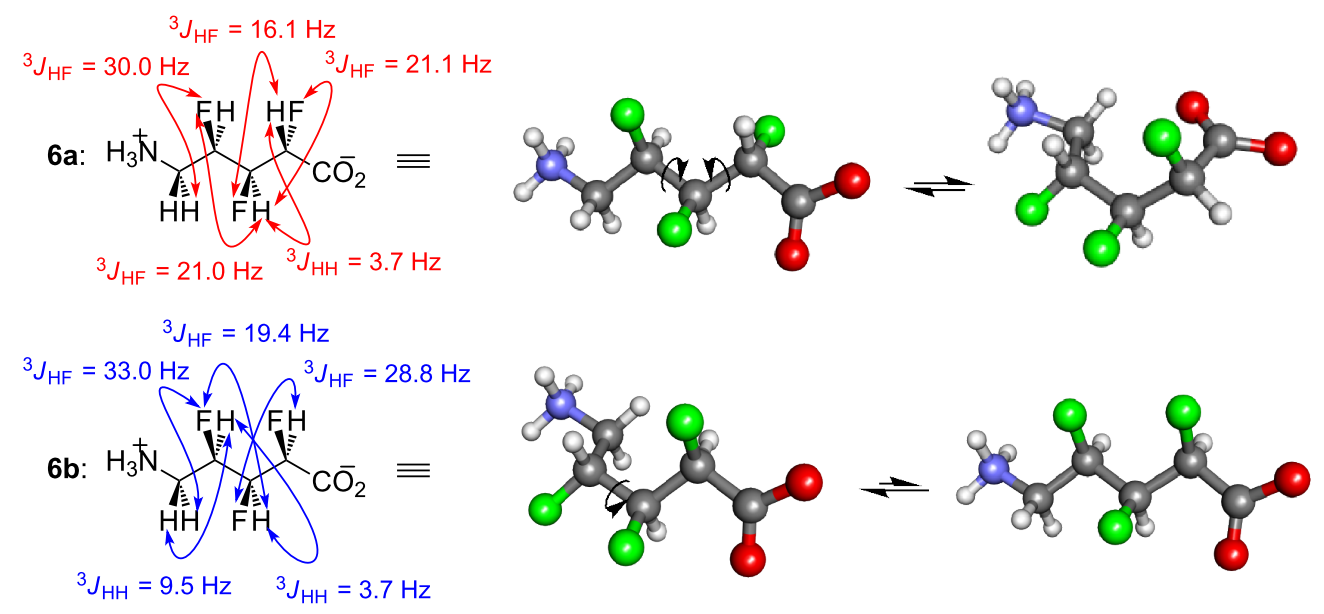

Figure 2: Selected $J$ values and the inferred molecular conformations of $\mathbf{6 a}$ and $\mathbf{6 b}$. 
diate in magnitude [42], suggesting that conformational averaging is occurring about both of these bonds. In contrast, the $J$ values about the $\mathrm{C} \gamma-\mathrm{C} \delta$ bond of $\mathbf{6 a}$ fall clearly into either gauche or anti ranges [42], suggesting that this part of the molecule is relatively rigid in solution. Overall, the pattern of large, small and intermediate $J$ values is consistent with two major conformations of 6a existing in equilibrium (Figure 2). The first conformer (left) has an extended zigzag structure. This matches the geometry that was observed in the X-ray crystal structure for the anti,syn-trifluoroalkane 40a [17]. The second conformer (right) has a bent shape which provides gauche alignments between all pairs of vicinal $\mathrm{C}-\mathrm{F}$ and $\mathrm{C}-\mathrm{N}$ bonds, whilst avoiding any 1,3-dipolar repulsions $[11,12,43]$.

The observed $J$ values for the all-syn trifluoro amino acid $\mathbf{6 b}$ also allowed its solution conformation to be deduced (Figure 2). The $J$ values about the $\mathrm{C} \alpha-\mathrm{C} \beta$ and $\mathrm{C} \gamma-\mathrm{C} \delta$ bonds of $\mathbf{6 b}$ mostly fall clearly into gauche or anti ranges, suggesting that these segments of the molecule are relatively rigid in solution. In contrast, the $J$ values about the $\mathrm{C} \beta-\mathrm{C} \gamma$ bond of $\mathbf{6 b}$ are more intermediate in magnitude (e.g., ${ }^{3} J_{\mathrm{HH}}=3.7 \mathrm{~Hz}$ ), suggesting that conformational averaging could be occurring about this bond. Overall, the pattern of large, small and intermediate $J$ values is consistent with two conformations of $\mathbf{6 b}$ existing in equilibrium (Figure 2). The first conformer (left) has a bent structure. This provides gauche alignments between all pairs of vicinal $\mathrm{C}-\mathrm{F}$ and $\mathrm{C}-\mathrm{N}$ bonds, whilst avoiding 1,3-dipolar repulsion $[11,12,43]$. The second suggested conformer of $\mathbf{6 b}$ (right) has an extended zigzag structure. This geometry is counterintuitive, because although it provides gauche alignments between all pairs of vicinal $\mathrm{C}-\mathrm{F}$ and $\mathrm{C}-\mathrm{N}$ bonds, it includes an unfavourable parallel alignment of the $\mathrm{C} \alpha-\mathrm{F}$ and $\mathrm{C} \gamma-\mathrm{F}$ bonds. The extended conformer of $\mathbf{6 b}$ may be a minor contributor only.

\section{Conclusion}

Full details have been presented of the efforts that were required to identify and optimise a synthetic route towards the $\delta$-amino acids $\mathbf{6 a}$ and $\mathbf{6 b}$, molecules which contain three vicinal $\mathrm{C}-\mathrm{F}$ bonds positioned stereospecifically along the backbone. Several synthetic approaches towards these challenging targets were investigated, involving both electrophilic and nucleophilic fluorination chemistry. The ultimately successful approach involved a modification of O'Hagan's method [34], in which a stereochemically-defined epoxy alcohol precursor underwent three sequential nucleophilic deoxyfluorination reactions. The solution-state geometries of amino acids $6 \mathbf{a}$ and $\mathbf{6 b}$ were probed through qualitative NMR $J$-based analyses, revealing that $\mathbf{6 a}$ and $\mathbf{6 b}$ exhibit distinct conformational behaviour. This suggests that these fluorinated backbone-extended amino acids might enjoy future applications, for example as shape-controlled building blocks for incorporation into bioactive peptides [16].

\section{Supporting Information}

\section{Supporting Information File 1}

Synthetic procedures and characterisation data of intermediated, NMR spectra and NMR simulations for 6a,b.

[http://www.beilstein-journals.org/bjoc/content/ supplementary/1860-5397-13-228-S1.pdf]

\section{Acknowledgements}

L.H. thanks the Australian Research Council for funding (ARC DE120101653; ARC DP140103962).

\section{References}

1. Cowell, S. M.; Lee, Y. S.; Cain, J. P.; Hruby, V. J. Curr. Med. Chem. 2004, 11, 2785-2798. doi:10.2174/0929867043364270

2. Kover, K. E.; Jiao, D.; Fang, S.; Hruby, V. J. J. Org. Chem. 1994, 59, 991-998. doi:10.1021/jo00084a014

3. Mathad, R. I.; Gessier, F.; Seebach, D.; Jaun, B. Helv. Chim. Acta 2005, 88, 266-280. doi:10.1002/hlca.200590008

4. Hu, X.-G.; Lawer, A.; Peterson, M. B.; Iranmanesh, H.; Ball, G. E.; Hunter, L. Org. Lett. 2016, 18, 662-665. doi:10.1021/acs.orglett.5b03592

5. Hunter, L.; Jolliffe, K. A.; Jordan, M. J. T.; Jensen, P.; Macquart, R. B. Chem. - Eur. J. 2011, 17, 2340-2343. doi:10.1002/chem.201003320

6. Wang, Z.; Hunter, L. J. Fluorine Chem. 2012, 143, 143-147. doi:10.1016/j.jluchem.2012.06.016

7. Yamamoto, I.; Jordan, M. J. T.; Gavande, N.; Doddareddy, M. R.; Chebib, M.; Hunter, L. Chem. Commun. 2012, 48, 829-831. doi:10.1039/C1CC15816C

8. Absalom, N.; Yamamoto, I.; O'Hagan, D.; Hunter, L.; Chebib, M. Aust. J. Chem. 2015, 68, 23-30. doi:10.1071/CH14456

9. Hunter, L.; Butler, S.; Ludbrook, S. B. Org. Biomol. Chem. 2012, 10, 8911-8918. doi:10.1039/c2ob26596f

10. Hu, X.-G.; Thomas, D. S.; Griffith, R.; Hunter, L. Angew. Chem., Int. Ed. 2014, 53, 6176-6179. doi:10.1002/anie.201403071

11. O'Hagan, D. Chem. Soc. Rev. 2008, 37, 308-319. doi:10.1039/B711844A

12. Hunter, L. Beilstein J. Org. Chem. 2010, 6, No. 38. doi:10.3762/bjoc.6.38

13. Thiehoff, C.; Rey, Y. P.; Gilmour, R. Isr. J. Chem. 2017, 57, 92-100. doi:10.1002/ijch.201600038

14. Zimmer, L. E.; Sparr, C.; Gilmour, R. Angew. Chem., Int. Ed. 2011, 50, 11860-11871. doi:10.1002/anie.201102027

15. Fox, S. J.; Gourdain, S.; Coulthurst, A.; Fox, C.; Kuprov, I.; Essex, J. W.; Skylaris, C.-K.; Linclau, B. Chem. - Eur. J. 2015, 21, 1682-1691. doi:10.1002/chem.201405317

16. Lawer, A.; Tai, J.; Jolliffe, K. A.; Fletcher, S.; Avery, V. M.; Hunter, L. Bioorg. Med. Chem. Lett. 2014, 24, 2645-2647. doi:10.1016/j.bmcl.2014.04.071

17. Cheerlavancha, R.; Lawer, A.; Cagnes, M.; Bhadbhade, M.; Hunter, L. Org. Lett. 2013, 15, 5562-5565. doi:10.1021/ol402756e

18. Beeson, T. D.; MacMillan, D. W. C. J. Am. Chem. Soc. 2005, 127, 8826-8828. doi:10.1021/ja051805f 
19. Steiner, D. D.; Mase, N.; Barbas, C. F., III. Angew. Chem., Int. Ed. 2005, 44, 3706-3710. doi:10.1002/anie.200500571

20. Marigo, M.; Fielenbach, D.; Braunton, A.; Kjærsgaard, A.; Jørgensen, K. A. Angew. Chem., Int. Ed. 2005, 44, 3703-3706. doi:10.1002/anie.200500395

21. Wisniewska, H. M.; Swift, E. C.; Jarvo, E. R. J. Am. Chem. Soc. 2013, 135, 9083-9090. doi:10.1021/ja4034999

22. Delfourne, E.; Kiss, R.; Le Corre, L.; Dujols, F.; Bastide, J.; Collignon, F.; Lesur, B.; Frydman, A.; Darro, F. J. Med. Chem. 2003, 46, 3536-3545. doi:10.1021/jm0308702

23. Horii, Z.-I.; Iwata, C.; Tamura, Y. J. Org. Chem. 1961, 26, 2273-2276. doi:10.1021/jo01351a031

24. Chu, C. K.; Ziegler, D. T.; Carr, B.; Wickens, Z. K.; Grubbs, R. H. Angew. Chem., Int. Ed. 2016, 55, 8435-8439. doi:10.1002/anie.201603424

25. Katcher, M. H.; Sha, A.; Doyle, A. G. J. Am. Chem. Soc. 2011, 133, 15902-15905. doi:10.1021/ja206960k

26. Miró, J.; del Pozo, C.; Toste, F. D.; Fustero, S. Angew. Chem. 2016, 128, 9191-9195. doi:10.1002/ange.201603046

27. Ando, K.; Kobayashi, T.; Uchida, N. Org. Lett. 2015, 17, 2554-2557. doi:10.1021/acs.orglett.5b01049

28. Nyffeler, P. T.; Durón, S. G.; Burkart, M. D.; Vincent, S. P.; Wong, C.-H. Angew. Chem., Int. Ed. 2005, 44, 192-212. doi:10.1002/anie.200400648

29. Enders, D.; Huttl, M. R. M. Synlett 2005, 991-993. doi:10.1055/s-2005-864813

30. Kwiatkowski, P.; Beeson, T. D.; Conrad, J. C.; MacMillan, D. W. C. J. Am. Chem. Soc. 2011, 133, 1738-1741. doi:10.1021/ja111163u

31. Bonnefous, C.; Payne, J. E.; Roppe, J.; Zhuang, H.; Chen, X.; Symons, K. T.; Nguyen, P. H.; Sablad, M.; Rozenkrants, N.; Zhang, Y.; Wang, L.; Severance, D.; Walsh, J. P.; Yazdani, N.; Shiau, A. K.; Noble, S. A.; Rix, P.; Rao, T. S.; Hassig, C. A.; Smith, N. D. J. Med. Chem. 2009, 52, 3047-3062. doi:10.1021/jm900173b

32. Andrés, M.; Buil, M. A.; Calbet, M.; Casado, O.; Castro, J.; Eastwood, P. R.; Eichhorn, P.; Ferrer, M.; Forns, P.; Moreno, I.; Petit, S.; Roberts, R. S. Bioorg. Med. Chem. Lett. 2014, 24, 5111-5117. doi:10.1016/j.bmcl.2014.08.026

33. Ward, R. A.; Bethel, P.; Cook, C.; Davies, E.; Debreczeni, J. E.; Fairley, G.; Feron, L.; Flemington, V.; Graham, M. A.; Greenwood, R.; Griffin, N.; Hanson, L.; Hopcroft, P.; Howard, T. D.; Hudson, J.; James, M.; Jones, C. D.; Jones, C. R.; Lamont, S.; Lewis, S.; Lindsay, N.; Roberts, K.; Simpson, I.; St-Gallay, S.; Swallow, S.; Tang, J.; Tonge, M.; Wang, Z.; Zhai, B. J. Med. Chem. 2017, 60, 3438-3450. doi:10.1021/acs.jmedchem.7b00267

34. Brunet, V. A.; Slawin, A. M. Z.; O'Hagan, D. Beilstein J. Org. Chem. 2009, 5, No. 61. doi:10.3762/bjoc.5.61

35. Štambaský, J.; Malkov, A. V.; Kočovský, P. J. Org. Chem. 2008, 73, 9148-9150. doi:10.1021/jo801874r

36. Bio, M. M.; Waters, M.; Javadi, G.; Song, Z. J.; Zhang, F.; Thomas, D. Synthesis 2008, 891-896. doi:10.1055/s-2008-1032181

37. Bresciani, S.; O'Hagan, D. Tetrahedron Lett. 2010, 51, 5795-5797. doi:10.1016/j.tetlet.2010.08.104

38. Banik, S. M.; Medley, J. W.; Jacobsen, E. N. Science 2016, 353, 51-54. doi:10.1126/science.aaf8078

39. Gao, Y.; Hanson, R. M.; Klunder, J. M.; Ko, S. Y.; Masamune, H.; Sharpless, K. B. J. Am. Chem. Soc. 1987, 109, 5765-5780. doi:10.1021/ja00253a032

40. Schüler, M.; O’Hagan, D.; Slawin, A. M. Z. Chem. Commun. 2005, 4324-4326. doi:10.1039/b506010a
41. Hudlicky, M. J. Fluorine Chem. 1989, 44, 345-359. doi:10.1016/S0022-1139(00)82802-X

42. O'Hagan, D.; Rzepa, H. S.; Schüler, M.; Slawin, A. M. Z. Beilstein J. Org. Chem. 2006, 2, No. 19. doi:10.1186/1860-5397-2-19

43. Scheidt, F.; Selter, P.; Santschi, N.; Holland, M. C.; Dudenko, D. V.; Daniliuc, C.; Mück-Lichtenfeld, C.; Hansen, M. R.; Gilmour, R. Chem. - Eur. J. 2017, 23, 6142-6149. doi:10.1002/chem.201604632

\section{License and Terms}

This is an Open Access article under the terms of the Creative Commons Attribution License (http://creativecommons.org/licenses/by/4.0), which permits unrestricted use, distribution, and reproduction in any medium, provided the original work is properly cited.

The license is subject to the Beilstein Journal of Organic Chemistry terms and conditions:

(http://www.beilstein-journals.org/bjoc)

The definitive version of this article is the electronic one which can be found at: doi:10.3762/bjoc. 13.228 